\title{
Dearomative Cycloadditions Utilizing an Organic Photosensitizer: An Alternative to Iridium Catalysis
}

\author{
Alessa B. Rolka and Burkhard Koenig* \\ Cite This: https://dx.doi.org/10.1021/acs.orglett.0c01622 \\ Read Online
}

ABSTRACT: A highly efficient, cheap, and organic alternative to the commonly used iridium photosensitizer $\left(\operatorname{Ir}\left[\mathrm{dF}\left(\mathrm{CF}_{3}\right) \mathrm{ppy}\right]_{2}(\mathrm{dtbpy})\right) \mathrm{PF}_{6}$ $([\mathbf{I r}-\mathbf{F}])$ is presented for visible-light energy transfer catalysis. The organic dye $2 \mathbf{C z P N}$ surpasses $[\mathbf{I r}-\mathbf{F}]$ in selectivity while at the same time being easily accessible in one step. The catalyst is recyclable and, due to its uncharged nature, soluble in nonpolar solvents such as toluene. Furthermore, the scope of molecular scaffolds that are compatible substrates for visible-light catalyzed dearomative cycloadditions is expanded.

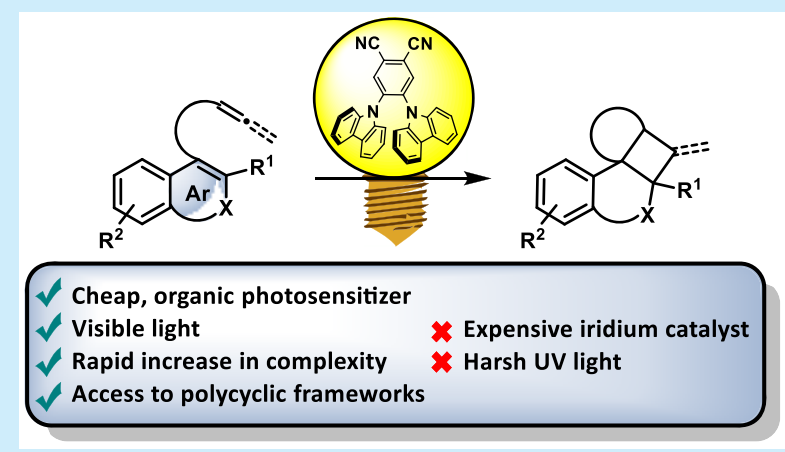

$\mathrm{O}$ ver the past few years, energy transfer catalysis has gained significant attention and has emerged as a powerful synthetic tool. ${ }^{1}$ The reasons for this are manifold, but of particular significance is the methodology's ability to rapidly generate high levels of molecular complexity. ${ }^{1 \mathrm{a}, 2}$ This is elegantly highlighted by the works of Glorius et al. ${ }^{3}$ and You et al. ${ }^{4}$ that demonstrate the generation of polycyclic cores by intramolecular dearomative cycloadditions of naphthol (Scheme 1A) and indole derivatives (Scheme 1B). The resulting molecular scaffolds often map onto natural product frameworks and are challenging to synthesize via other means. ${ }^{5}$ One alternative to accessing these structures is the direct excitation of substrates by UV light. However, this method often leads to unwanted side reactions and poor selectivity. ${ }^{6}$ By utilizing visible light and suitable photosensitizers to indirectly activate molecules, the need for UV light and/or other harsh reaction conditions can be avoided.

Key to the success of such a mild visible-light catalyzed process is the careful selection of a photosensitizer whose triplet energy upon excitation with visible light and intersystem crossing matches the targeted molecules. In the past, photocatalysts (PCs) with sufficiently high triplet energies for challenging dearomative processes of the type depicted in Scheme 1 have been largely limited to iridium-based systems utilizing $\left(\operatorname{Ir}\left[\mathrm{dF}\left(\mathrm{CF}_{3}\right) \text { ppy }\right]_{2}(\mathrm{dtbpy})\right) \mathrm{PF}_{6}([\mathbf{I r}-\mathbf{F}])$ (Scheme 1C) and its derivatives. ${ }^{3,4,7}$ This catalyst, which has also been shown to be effective in other catalytic energy transfer processes, benefits from a long-lived excited triplet state and a high triplet energy. ${ }^{1,8,9}$ Despite these desirable traits, iridium catalysis has several significant drawbacks that limit its widespread use. On the economic side, iridium has the distinction of being the rarest of the rare earth metals and has a correspondingly high price that can make the cost of the catalyst prohibitively expensive. ${ }^{10}$ Furthermore, the presence of transition metals in pharmaceuticals is highly regulated, and use of an iridium photocatalyst in late stage steps is undesirable in regards to industrial applications of these complexity generating processes. ${ }^{11}$ Finally, the charged nature of the expensive catalyst complicates its recyclability ${ }^{8 \mathrm{~d}, 12}$ as well as limits the catalyst's solubility in many common nonpolar solvents. $^{10 a}$

This work aims to address these problems by avoiding iridium and offers a highly effective, cheap, neutral, and organic alternative for the widely utilized $[\mathbf{I r}-\mathbf{F}]$ photosensitizer. Based upon OLED research ${ }^{13}$ and reports about the photochemical and photophysical properties of organic dyes, we were drawn to 1,2-bis(carbazol-9-yl)-4,5-dicyanobenzene (2CzPN) (Scheme 1D) as a promising candidate for this task. ${ }^{14}$ Specifically, the high triplet energy of this system at 60.6 $\mathrm{kcal} / \mathrm{mol}$ (corresponding to $\left.T_{1}=2.63 \mathrm{eV}\right)^{14 \mathrm{~d}}$ as well as the prior use of this catalyst for photochromism ${ }^{15}$ led us to explore its performance in the dearomatization reactions of aforementioned naphthol and indole derivatives.

The dearomative cycloaddition of naphthol 1 a was used as a model reaction to investigate the organic catalyst $2 \mathrm{CzPN}$ (Table 1). To begin, 1a and $5 \mathrm{~mol} \% \mathbf{2 C z P N}$ were irradiated with $455 \mathrm{~nm}$ light in 1,4-dioxane at room temperature. Under

Received: May 12, 2020 
Scheme 1. Previously Reported Dearomatizations of Naphthol Derivatives $(A)^{3}$ and Indole Derivatives $(B)^{4}$ and Structure of the Organic Alternative $2 \mathrm{CzPN}$ (D) to ([IrF]) (C)

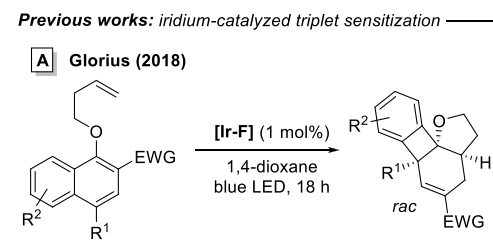

B You (2019)
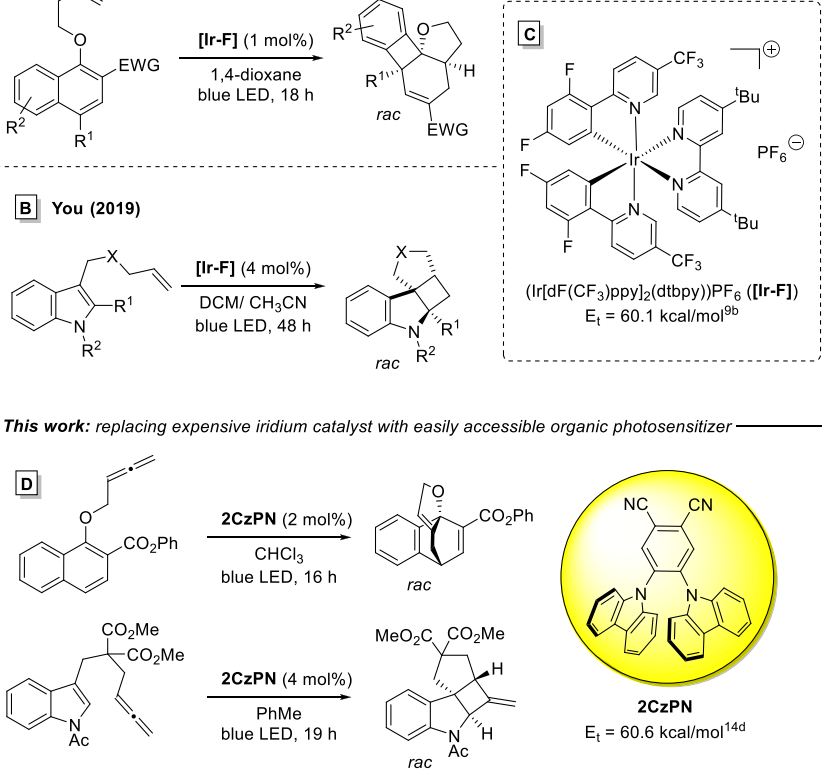

Table 1. Optimization Studies for the Organocatalytic Dearomatization of Naphthol $1 \mathrm{a}^{a}$
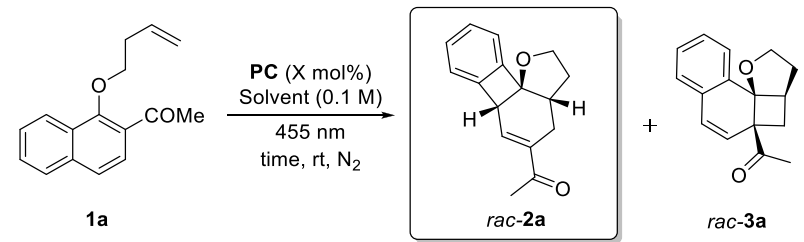

\begin{tabular}{|c|c|c|c|c|c|}
\hline entry & $\mathrm{PC}$ & $\mathrm{X}$ & time $(\mathrm{h})$ & solvent & ratio $2 \mathrm{a}: 3 \mathrm{a}^{b}$ \\
\hline $1^{c}$ & $2 \mathrm{CzPN}$ & 5 & 17 & 1,4-dioxane & $1.2: 1$ \\
\hline $2^{d}$ & $2 \mathrm{CzPN}$ & 5 & 17 & 1,4-dioxane & $1.2: 1$ \\
\hline 3 & $2 \mathrm{CzPN}$ & 5 & 17 & $\mathrm{PhMe}$ & $1.8: 1$ \\
\hline 4 & $2 \mathrm{CzPN}$ & 5 & 17 & $\mathrm{CHCl}_{3}$ & $16: 1$ \\
\hline 5 & $2 \mathrm{CzPN}$ & 1 & 14 & $\mathrm{CHCl}_{3}$ & $16(94 \%)^{e}: 1$ \\
\hline 6 & $2 \mathrm{CzPN}$ & 0.5 & 14 & $\mathrm{CHCl}_{3}$ & $3: 1$ \\
\hline 7 & $2 \mathrm{CzPN}$ & 0.2 & 14 & $\mathrm{CHCl}_{3}$ & $1: 1.6$ \\
\hline $8^{f}$ & $2 \mathrm{CzPN}$ & 1 & 17 & $\mathrm{CHCl}_{3}$ & $1: 20$ \\
\hline 9 & TX & 5 & 17 & $\mathrm{CHCl}_{3}$ & $\mathrm{~N} / \mathrm{A}^{g}$ \\
\hline 10 & & & 17 & 1,4-dioxane & $\mathrm{N} / \mathrm{A}^{g}$ \\
\hline
\end{tabular}

${ }^{a}$ Reactions were run at a $0.2 \mathrm{mmol}$ scale. ${ }^{b}$ Determined by ${ }^{1} \mathrm{H}$-crude NMR ratio. Entries with a ratio showed no other proton signals and full conversion with isolation of a mixture of $\mathbf{2 a}$ and $\mathbf{3 a}$ in near quantitative yield. ${ }^{c} 0.04 \mathrm{M}^{d} \lambda_{\max }=405 \mathrm{~nm}$ light was used instead of $\lambda_{\max }=455 \mathrm{~nm}$. ${ }^{e} 94 \%$ isolated yield confirms the use of the NMR ratio is a reliable indication of yield. $f_{0.1}$ equiv of $\mathrm{Sc}(\mathrm{OTf})_{3}$. ${ }^{g}$ Not applicable. No conversion of starting material.

these conditions, we were pleased to see full conversion of the starting material but with poor selectivity, as measured by the ratio of 2a:3a (entry 1). This reaction proceeds via two sequential triplet energy excitation processes. First, excitation of $1 \mathrm{a}$ results in a $[2+2]$ cycloaddition to form $3 \mathbf{a}$, while subsequent excitation of $3 a$ followed by rearrangement furnishes $2 \mathbf{a}$. The ultimate ratio of $\mathbf{2 a} \mathbf{a} \mathbf{3 a}$ is influenced by the triplet energy of the catalyst and the rate of energy transfer. For the complete mechanism, see Supporting Information 5.1.

Lowering the wavelength from 455 to $405 \mathrm{~nm}$ did not influence selectivity (entry 2). After a brief screening of solvents, it was found that chloroform was ideal, leading to formation of 2 a with a high selectivity of 16:1 (entry 4). We were able to lower both the reaction time to $14 \mathrm{~h}$ and the catalyst loading to $1 \mathrm{~mol} \%$ without impacting the reaction (entry 5). Further lowering the catalyst loading resulted in worse selectivity (entries 6 and 7). Through the addition of a Lewis acidic additive, the reaction could be directed toward the selective formation of $\mathbf{3 a}$ (entry 8 ). However, this observed effect proved not to be general to other substrates.

Therefore, $1 \mathrm{~mol} \% \mathbf{2 C z P N}$ in chloroform irradiated at 455 $\mathrm{nm}$ for $14 \mathrm{~h}$ were chosen as the optimized conditions, giving $2 \mathrm{a}$ in $94 \%$ isolated yield as a single diastereomer and with a $2 \mathrm{a}: 3 \mathbf{a}$ ratio of 16:1 (entry 5). In comparison, the optimized conditions of Glorius utilizing $1 \mathrm{~mol} \%[\mathbf{I r}-\mathbf{F}]$ (1,4-dioxane; $0.04 \mathrm{M} ; 18 \mathrm{~h} ; 455 \mathrm{~nm}$ ) achieved a ratio of $6: 1$ with a yield of $86 \%$, ${ }^{3}$ showing that $2 \mathrm{CzPN}$ is able to improve the selectivity of the reaction. Control experiments utilizing the organic photosensitizer thioxanthone (TX), which absorbs at lower wavelengths $^{16}$ (entry 9), and irradiation without any catalyst (entry 10) resulted in no conversion, proving the necessity of 2CzPN.

With optimized conditions in hand, tailored to the organic dye $2 \mathrm{CzPN}$, the substrate scope was investigated to better compare $\mathbf{2 C z P N}$ with $[\mathbf{I r}-\mathbf{F}]$. To do so, five substrates were selected with different electronic and steric properties at the activating group $\mathrm{R}^{1}$ as well as at the naphthyl ring $\mathrm{R}^{2}$ (Scheme 2 ). For ease of comparison, the already reported yields with 1 mol \% of the iridium catalyst $[\mathbf{I r}-\mathbf{F}]$ are included in brackets. Based upon these yields, it is evident that $2 \mathrm{CzPN}$ is able to catalyze the dearomatization of naphthols in a highly efficient fashion that is comparable or superior to $[\mathbf{I r}-\mathbf{F}]$.

Scheme 2. Substrate Scope of Naphthols ${ }^{a}$
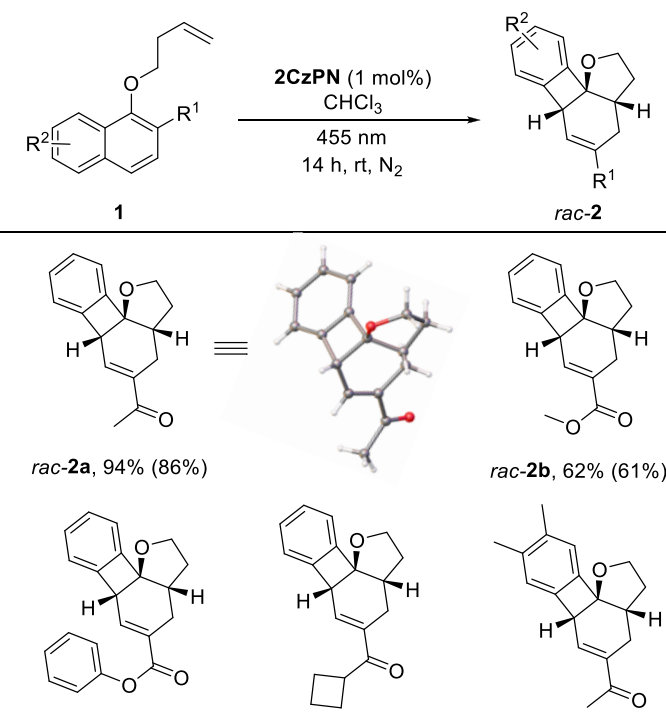

rac-2b, $62 \%(61 \%)$

rac-2c, $99 \%(92 \%)$

rac-2d, $76 \%^{\mathrm{b}}(72 \%)$

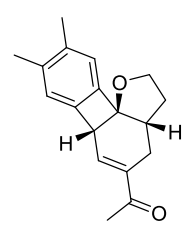

rac-2e, $70 \%^{\mathrm{b}}(47 \%)$

${ }^{a}$ Yields are isolated yields. Yields in brackets are isolated yields of the originally reported reactions with $1 \mathrm{~mol} \%[\mathbf{I r}-\mathbf{F}] .^{3}$ Reactions were run on a $0.2 \mathrm{mmol}$ scale at $0.1 \mathrm{M}$. ${ }^{b}$ Two mol \% 2CzPN, $42 \mathrm{~h}$. 
Reactions with $2 \mathrm{CzPN}$ readily scale and could be performed equally effectively in multiple gram quantities with only $1 \mathrm{~mol}$ $\%$ catalyst (Scheme 3A). We were also able to take advantage

Scheme 3. Scale-up of the Reaction with Recycling of Catalyst (A) and Subsequent Reaction with Recycled Catalyst (B)

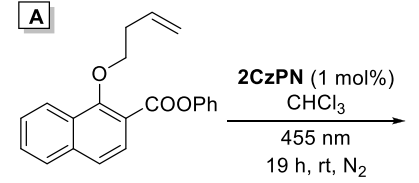

$1 \mathrm{c}$

$7.00 \mathrm{mmol}$

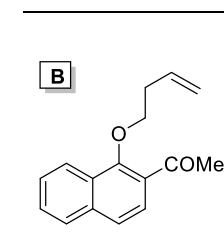

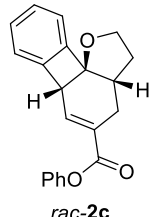

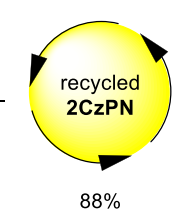

$88 \%$
$1 \mathrm{a}$

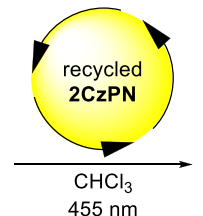

$14 \mathrm{~h}, \mathrm{rt}, \mathrm{N}_{2}$

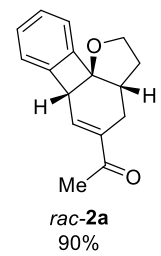

of 2CzPN's neutral charge to readily recycle the catalyst by means of column chromatography in $88 \%$ yield, and the recycled catalyst shows no change in activity upon reuse (Scheme 3B).

Motivated by the positive results, we explored the compatibility of $2 \mathrm{CzPN}$ with the dearomatization of indole derivates. This class of compounds represents a more challenging test due to their increased triplet energy. While the optimized conditions for naphthol dearomatization resulted in very poor conversion of $4 a$, it was found that utilization of toluene as solvent allowed the reaction to proceed in high yields (Supporting Information 3.1). It is thought that the use of the less polar toluene solvent inhibits electron transfer from the indole substrate to the excited photocatalyst that preferentially occurs over triplet sensitization in polar solvents.

The ability to utilize nonpolar solvents with $2 \mathrm{CzPN}$ highlights another advantage of this organic photosensitizer over the $[\mathbf{I r}-\mathbf{F}]$ system, which is only minimally soluble in toluene $(100-1000 \mathrm{ppm})^{10 a}$ and other nonpolar solvents due to its charged nature (Table 2). A comparison of the maximum solubility in a range of different solvents revealed a more than 100 times higher solubility of $2 \mathbf{C z P N}$ in toluene. It is noteworthy that the organic catalyst retains high solubility in polar solvents.

Table 2. Maximum Solubilities of $[\mathrm{Ir}-\mathrm{F}]$ and $2 \mathrm{CzPN}$ in Common Organic Solvents ${ }^{a}$

\begin{tabular}{lcc}
\multicolumn{1}{c}{ solvent } & {$[\mathbf{I r}-\mathbf{F}]^{b}$} & $\mathbf{2 C z P N}^{c}$ \\
PhMe & $7.0 \times 10^{-5}$ & $1.3 \times 10^{-2}$ \\
1,4-dioxane & $c$ & $1.6 \times 10^{-2}$ \\
DCM & $2.2 \times 10^{-4}$ & $8.3 \times 10^{-2}$ \\
methyl tert-butyl ether & $5.6 \times 10^{-3}$ & $9.2 \times 10^{-4}$ \\
DMSO & $7.0 \times 10^{-5}$ & $1.6 \times 10^{-2}$
\end{tabular}

${ }^{a}$ Maximum solubility given as concentration (Molar). ${ }^{b}$ As reported by the group of Weaver. ${ }^{10 a}{ }^{c}$ See Supporting Information 3.4.
To demonstrate the efficiency of our conditions, a scope of indoles was investigated (Scheme 4). Just as with $[\mathbf{I r}-\mathbf{F}]$,

Scheme 4. Substrate Scope of Indoles ${ }^{a}$

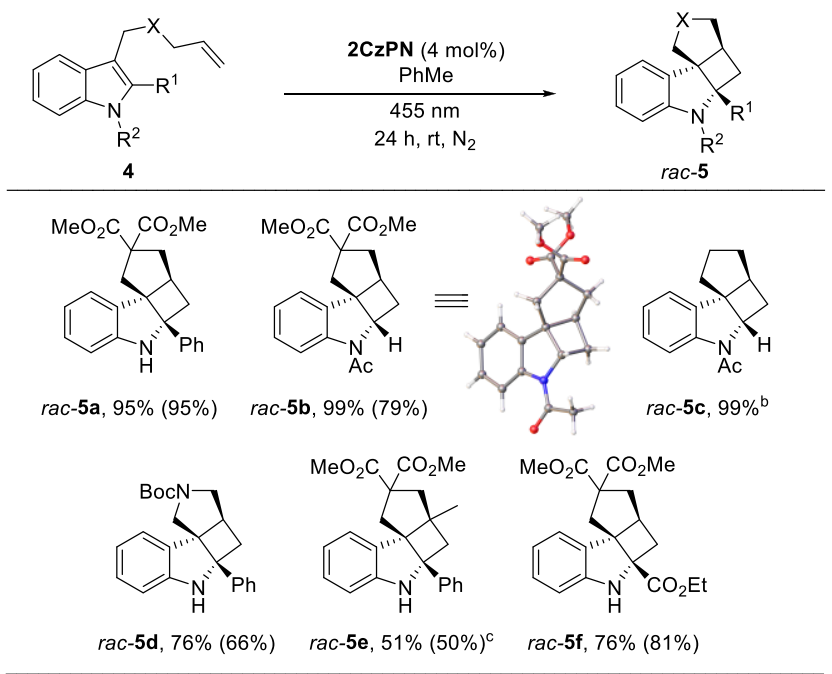

${ }^{a}$ Yields are isolated yields. Yields in brackets are isolated yields of the originally reported reactions with $[\mathbf{I r}-\mathbf{F}] .^{4}$ Reactions run on a 0.05 mmol scale at $0.0125 \mathrm{M}$. ${ }^{b}$ Nineteen hours. ${ }^{c}$ Originally reported reaction with $8 \mathrm{~mol} \%[\mathbf{I r}-\mathbf{F}]$.

substitution at the 2-position was well-tolerated (5a, 5d, 5e, and 5f), as was the use of a more sterically hindered 1,1disubstituted alkene (5e). The reaction proceeds utilizing substrates bearing the free indole $\mathrm{N}-\mathrm{H}$ or an $\mathrm{N}$-acetyl group, with the highest yields observed with the acetylated substrates $(\mathbf{5 b}, \mathbf{5 c})$. These nearly quantitative yields are thought to be attributed to the electron-withdrawing nature of the acetyl group, which lowers the triplet energy of the substrates while at the same time increasing their oxidation potential to limit redox events with the catalyst. Using an $\mathrm{N}$-acetylated substrate, we were especially delighted to find that high levels of reactivity could be obtained without the bulky diester linker which facilitates ring closure via the Thorpe-Ingold-Effect (5c). ${ }^{17}$ Once again, for all substrates tested, the organic photosensitizer proved to be comparable or superior to $[\mathbf{I r}-\mathbf{F}]$ at equivalent catalyst loadings. ${ }^{4}$

Having established that the organic catalyst is an effective replacement for $[\mathbf{I r}-\mathbf{F}]$, we sought to test the organic photocatalyst on more challenging cases containing allene cycloaddition partners that have the potential to form highly strained methylencyclobutane products. ${ }^{18}$ This class of substrates is particularly intriguing due to the presence of an olefin in the product that can serve as a functional group handle for further structural elaboration.

Whereas the direct UV excitation of aromatic rings followed by their trapping with allenes has been reported, little has been done within the field of visible-light triplet-sensitized chemistry. ${ }^{18} \mathrm{~A}$ rare example of triplet-sensitized chemistry involving allenes is the work of Arai and Ohkuma, where 50 mol \% of $3^{\prime}, 4^{\prime}$-dimethoxyacetophenone sensitizer was required in the dearomative cycloaddition of indole derivatives. ${ }^{18 \mathrm{~d}, \mathrm{e}}$ However, in addition to the high catalyst loading, a highpressure mercury lamp was necessary (Supporting Information 5.2). Inspired by their work, we synthesized allene 6 to investigate whether $\mathbf{2 C z P N}$ can overcome these significant 
limitations. Applying the same optimized conditions as for $\mathbf{4 b}$, we were pleased to see full conversion of 6 to the dearomatized products 7 and 8 in high yield and with a ratio of 5.3:1 (Scheme 5).

Scheme 5. Formation of Methylencyclobutane Products from Allene Substituted Indole $6^{a}$

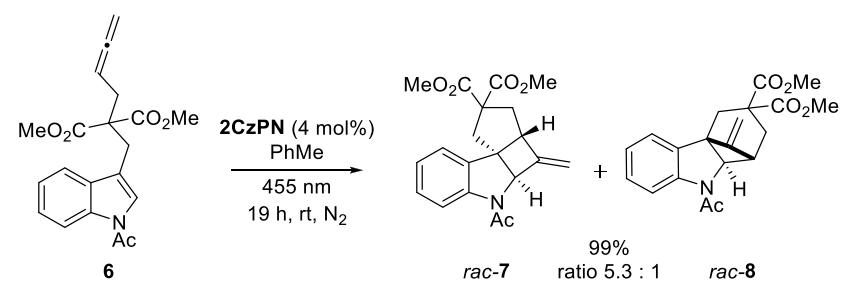

${ }^{a}$ Isolated yield. Reaction has previously not been reported with [ $\mathbf{I r}-$ F]. The reaction was run on a $0.05 \mathrm{mmol}$ scale at $0.0125 \mathrm{M}$.

We next explored the previously unreported visible-light photochemistry of naphthol allene derivatives. When treating naphthol ketone 9a with slightly modified conditions described above for the dearomatization of naphthols, we were surprised to obtain the aromatic cyclic acetal 10a as the main product in $61 \%$ yield. The product was confirmed by a single crystal X-ray analysis (Supporting Information 7.3) and supported by the literature-known UV-photochemistry of allenyl salicylaldehydes. ${ }^{18 b, c}$ We believe that $10 a$ is formed via dearomatized intermediate 12 that upon 1,3-allylic transposition yields product 10a. As a minor side product under these conditions, dihydrofuran 11a was also obtained via a 1,4-cycloaddition. By exchanging the acetyl group (9a) with a phenyl ester (9b), only the dearomatized product $\mathbf{1 1 b}$ was observed in $81 \%$ yield (Scheme 6).

Scheme 6. Dearomative Cycloaddition of Allene-Substituted Naphthol Derivatives ${ }^{a}$

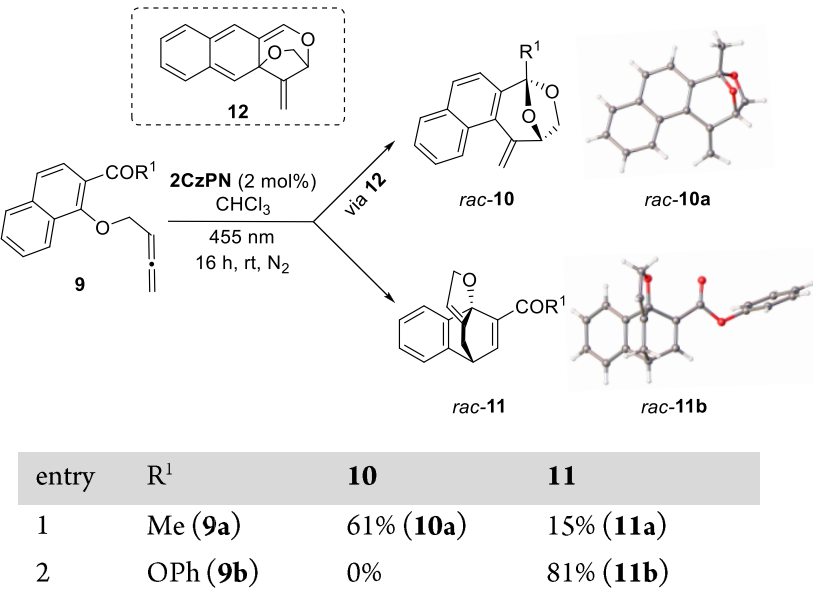

${ }^{a}$ Yields are isolated yields. Reaction has previously not been reported with $[\mathbf{I r}-\mathbf{F}]$. Reactions were run on a $0.1 \mathrm{mmol}$ scale at $0.05 \mathrm{M}$.

In conclusion, we have shown $2 \mathrm{CzPN}$ to be a highly effective and general triplet sensitizer that can serve as an effective replacement for the expensive $[\mathbf{I r}-\mathbf{F}]$ catalyst that has until now been the preferred sensitizer to activate substrates with high triplet energies via visible light. Through a series of direct comparisons, the organic catalyst consistently matched or outperformed the iridium catalyst in dearomative cycloadditions. The organic dye was furthermore applied in the previously not reported visible-light induced photocycloaddition of naphthol and indole allenes, giving rise to complex polycyclic frameworks. The catalyst itself is readily synthesized in gram quantities in one step from cheap and commercial starting materials and is bench-stable. Its uncharged nature allows for solubility in a broad range of polar and nonpolar solvents and for easy recovery and reuse of the catalyst via column chromatography. Finally, reactions performed with 2CzPN have proven to be readily amenable to large, multigram scales. We believe that the presented work will facilitate a broader use of visible-light mediated triplet-sensitized reactions through the identification of a cheap organic replacement for the previously utilized iridium catalyst.

\section{ASSOCIATED CONTENT}

Supporting Information

The Supporting Information is available free of charge at https://pubs.acs.org/doi/10.1021/acs.orglett.0c01622.

Experimental details, characterization data, and spectra (PDF)

\section{Accession Codes}

CCDC 1998653-1998654, 1998663, and 2000974 contain the supplementary crystallographic data for this paper. These data can be obtained free of charge via www.ccdc.cam.ac.uk/ data_request/cif, or by emailing data_request@ccdc.cam.ac. uk, or by contacting The Cambridge Crystallographic Data Centre, 12 Union Road, Cambridge CB2 1EZ, UK; fax: +44 1223336033.

\section{AUTHOR INFORMATION}

\section{Corresponding Author}

Burkhard Koenig - Institute of Organic Chemistry, University of Regensburg, 93053 Regensburg, Germany; 이이.org/ 0000-0002-6131-4850; Email: burkhard.koenig@ chemie.uni-regensburg.de

\section{Author}

Alessa B. Rolka - Institute of Organic Chemistry, University of Regensburg, 93053 Regensburg, Germany

Complete contact information is available at:

https://pubs.acs.org/10.1021/acs.orglett.0c01622

\section{Notes}

The authors declare no competing financial interest.

\section{ACKNOWLEDGMENTS}

This work was supported by the German Science Foundation (DFG, KO 1537/18-1). We would like to thank the Fonds der Chemischen Industrie (FCI) and the Studienstiftung des deutschen Volkes for financial support. Furthermore, we would like to thank Anamitra Chatterjee (University of Regensburg) for the synthesis of compound $\mathbf{4 d}$. We are also grateful to Birgit Hischa (University of Regensburg) for X-ray crystallographic analysis.

\section{REFERENCES}

(1) For a recent review on energy transfer mediated reactions, see: (a) Zhou, Q.-Q.; Zou, Y.-Q.; Lu, L.-Q.; Xiao, W.-J. Visible-LightInduced Organic Photochemical Reactions through Energy-Transfer 
Pathways. Angew. Chem., Int. Ed. 2019, 58, 1586-1604. For a tutorial review covering the principles and applications of energy transfer catalysis, see: (b) Strieth-Kalthoff, F.; James, M. J.; Teders, M.; Pitzer, L.; Glorius, F. Energy transfer catalysis mediated by visible light: principles, applications, directions. Chem. Soc. Rev. 2018, 47, 71907202.

(2) For selected reviews, see: (a) Sarkar, D.; Bera, N.; Ghosh, S. [2+ 2] Photochemical Cycloaddition in Organic Synthesis. Eur. J. Org. Chem. 2020, 2020, 1310-1326. (b) Okumura, M.; Sarlah, D. VisibleLight-Induced Dearomatizations. Eur. J. Org. Chem. 2020, 2020, 1259-1273. (c) Roche, S. P.; Porco, J. A. Dearomatization Strategies in the Synthesis of Complex Natural Products. Angew. Chem., Int. Ed. 2011, 50, 4068-4093.

(3) James, M. J.; Schwarz, J. L.; Strieth-Kalthoff, F.; Wibbeling, B.; Glorius, F. Dearomative Cascade Photocatalysis: Divergent Synthesis through Catalyst Selective Energy Transfer. J. Am. Chem. Soc. 2018, 140, 8624-8628.

(4) Zhu, M.; Zheng, C.; Zhang, X.; You, S.-L. Synthesis of Cyclobutane-Fused Angular Tetracyclic Spiroindolines via VisibleLight-Promoted Intramolecular Dearomatization of Indole Derivatives. J. Am. Chem. Soc. 2019, 141, 2636-2644.

(5) For a review covering natural cyclobutane-containing alkaloids, see (a) Dembitsky, V. M. Bioactive cyclobutane-containing alkaloids. J. Nat. Med. 2007, 62, 1-33. For selected reviews featuring the alternative synthesis of complex molecular scaffolds, see: (b) Zheng, C.; You, S.-L. Catalytic asymmetric dearomatization (CADA) reaction-enabled total synthesis of indole-based natural products. Nat. Prod. Rep. 2019, 36, 1589-1605. (c) Sebren, L. J.; Devery, J. J.; Stephenson, C. R. J. Catalytic Radical Domino Reactions in Organic Synthesis. ACS Catal. 2014, 4, 703-716. (d) Pape, A. R.; Kaliappan, K. P.; Kündig, E. P. Transition-Metal-Mediated Dearomatization Reactions. Chem. Rev. 2000, 100, 2917-2940. For selected papers featuring natural products related to the scaffolds accessed by energy transfer catalysis, see: (e) Hara, H.; Maruyama, N.; Yamashita, S.; Hayashi, Y.; Lee, K. H.; Bastow, K. F.; Marumoto, C. R.; Imakura, Y. Elecanacin, a Novel New Naphthoquinone from the Bulb of Eleutherine americana. Chem. Pharm. Bull. 1997, 45, 1714-1716. (f) Jamart-Grégoire, B.; Fort, Y.; Zouaoui, M. A.; Caubère, P. Efficient Synthesis of New Benzocyclobutenic Phenethylamines. Synth. Commun. 1993, 23, 885-894. (g) Carre, M. C.; Youlassani, A.; Caubere, P.; Saint-Aubin-Floch, A.; Blanc, M.; Advenier, C. Synthesis of a Novel Series of (Aryloxy)propanolamines: New Selective Beta 2blocking Agents. J. Med. Chem. 1984, 27, 792-799.

(6) For selected reviews, see: (a) Poplata, S.; Tröster, A.; Zou, Y.-Q.; Bach, T. Recent Advances in the Synthesis of Cyclobutanes by Olefin $[2+2]$ Photocycloaddition Reactions. Chem. Rev. 2016, 116, 97489815. (b) Yoon, T. P.; Ischay, M. A.; Du, J. Visible light photocatalysis as a greener approach to photochemical synthesis. Nat. Chem. 2010, 2, 527-532. (c) Hoffmann, N. Photochemical Cycloaddition between Benzene Derivatives and Alkenes. Synthesis 2004, 4, 481-495. (d) Bach, T. Stereoselective Intermolecular $[2+2]$-Photocycloaddition Reactions and Their Application in Synthesis. Synthesis 1998, 1998, 683-705. (e) Fleming, S. A.; Bradford, C. L.; Gao, J. J. Regioselective and Stereoselective $[2+2]$ Photocycloadditions. In Organic Photochemistry, Molecular and Supramolecular Photochemistry; Ramamurthy, V., Schanze, K. S., Eds.; Dekker: New York, 1997; Vol. 1, p 187. (f) Crimmins, M. T.; Reinhold, T. L. Enone Olefin [2+2] Photochemical Cycloadditions. Org. React. 1993, 44, 297. (g) Bauslaugh, P. G. Photochemical Cycloaddition Reactions of Enones to Alkenes; Synthetic Applications. Synthesis 1970, 1970, 287-300. For an example of a UV-light induced dearomatization of naphthol derivatives, see: (h) Wagner, P. J. Photoinduced Ortho $[2+2]$ Cycloaddition of Double Bonds to Triplet Benzenes. Acc. Chem. Res. 2001, 34, 1-8.

(7) (a) Oderinde, M. S.; Mao, E.; Ramirez, A.; Pawluczyk, J.; Jorge, C.; Cornelius, L. A. M.; Kempson, J.; Vetrichelvan, M.; Pitchai, M.; Gupta, A.; Gupta, A. K.; Meanwell, N. A.; Mathur, A.; Dhar, T. G. M. Synthesis of Cyclobutane-Fused Tetracyclic Scaffolds via Visible-Light Photocatalysis for Building Molecular Complexity. J. Am. Chem. Soc.
2020, 142, 3094-3103. Recently, an example of gadolinium photocatalysis was published: (b) Ma, J.; Schäfers, F.; Daniliuc, C.; Bergander, K.; Strassert, C. A.; Glorius, F. Gadolinium Photocatalysis: Dearomative $[2+2]$ Cycloaddition/Ring-Expansion Sequence with Indoles. Angew. Chem., Int. Ed. 2020, 59, 2-9. For an example of rhodium-catalyzed deraomatization of benzofuranes and benzothiophenes, see: (c) Hu, N.; Jung, H.; Zheng, Y.; Lee, J.; Zhang, L.; Ullah, Z.; Xie, X.; Harms, K.; Baik, M.-H.; Meggers, E. Catalytic Asymmetric Dearomatization by Visible-Light-Activated [2+2] Photocycloaddition. Angew. Chem., Int. Ed. 2018, 57, 6242-6246. For an example of dearomatization of molecules with a lower degree of aromaticity utilizing an organic sensitizer, see: (d) Tröster, A.; Alonso, R.; Bauer, A.; Bach, T. Enantioselective Intermolecular $[2+2]$ Photocycloaddition Reactions of $2(1 \mathrm{H})$-Quinolones Induced by Visible Light Irradiation. J. Am. Chem. Soc. 2016, 138, 7808-7811.

(8) For selected examples utilizing $[\mathbf{I r}-\mathbf{F}]$ as an energy transfer catalyst, see: (a) Becker, M. R.; Richardson, A. D.; Schindler, C. S. Functionalized azetidines via visible light-enabled aza Paternò-Büchi reactions. Nat. Commun. 2019, 10, 5095. (b) Soni, V. K.; Lee, S.; Kang, J.; Moon, Y. K.; Hwang, H. S.; You, Y.; Cho, E. J. Reactivity Tuning for Radical-Radical Cross-Coupling via Selective Photocatalytic Energy Transfer: Access to Amine Building Blocks. ACS Catal. 2019, 9, 10454-10463. (c) Patra, T.; Mukherjee, S.; Ma, J.; Strieth-Kalthoff, F.; Glorius, F. Visible-Light-Photosensitized Aryl and Alkyl Decarboxylative Functionalization Reactions. Angew. Chem., Int. Ed. 2019, 58, 10514-10520. (d) Ma, J.; Strieth-Kalthoff, F.; Dalton, T.; Freitag, M.; Schwarz, J. L.; Bergander, K.; Daniliuc, C.; Glorius, F. Direct Dearomatization of Pyridines via an Energy-Transfer-Catalyzed Intramolecular [4 + 2] Cycloaddition. Chem. 2019, 5, 2854-2864. (e) Chatterjee, A.; König, B. Birch-Type Photoreduction of Arenes and Heteroarenes by Sensitized Electron Transfer. Angew. Chem., Int. Ed. 2019, 58, 14289-14294. (f) Teders, M.; Henkel, C.; Anhäuser, L.; Strieth-Kalthoff, F.; Gómez-Suárez, A.; Kleinmans, R.; Kahnt, A.; Rentmeister, A.; Guldi, D.; Glorius, F. The energy-transfer-enabled biocompatible disulfide-ene reaction. Nat. Chem. 2018, 10, 981-988. (g) Sun, Z.; Kumagai, N.; Shibasaki, M. Photocatalytic $\alpha$-Acylation of Ethers. Org. Lett. 2017, 19, 3727-3730. (h) Bagal, D. B.; Park, S.-W.; Song, H.-J.; Chang, S. Visible light sensitization of benzoyl azides: cascade cyclization toward oxindoles via a non-nitrene pathway. Chem. Commun. 2017, 53, 8798-8801. (i) Pagire, S. K.; Hossain, A.; Traub, L.; Kerres, S.; Reiser, O. Photosensitised regioselective [2+ 2]-cycloaddition of cinnamates and related alkenes. Chem. Commun. 2017, 53, 12072-12075. (j) Zhao, J.; Brosmer, J. L.; Tang, Q.; Yang, Z.; Houk, K. N.; Diaconescu, P. L.; Kwon, O. Intramolecular Crossed $[2+2]$ Photocycloaddition through Visible Light-Induced Energy Transfer. J. Am. Chem. Soc. 2017, 139, 9807-9810. (k) Heitz, D. R.; Tellis, J. C.; Molander, G. A. Photochemical Nickel-Catalyzed C-H Arylation: Synthetic Scope and Mechanistic Investigations. J. Am. Chem. Soc. 2016, 138, 12715-12718. (1) Xia, X.-D.; Ren, Y.-L.; Chen, J.-R.; Yu, X.-L.; Lu, L.-Q.; Zou, Y.-Q.; Wan, J.; Xiao, W.-J. Phototandem Catalysis: Efficient synthesis of 3-Ester-3-hydroxy-2oxindoles by a Visible Light-Induced Cyclization of Diazoamides through an Aerobic Oxidation Sequence. Chem. - Asian J. 2015, 10, 124-128. (m) Hurtley, A. E.; Lu, Z.; Yoon, T. P. $[2+2]$ Cycloaddition of 1,3-Dienes by Visible Light Photocatalysis. Angew. Chem., Int. Ed. 2014, 53, 8991-8994. (n) Lu, Z.; Yoon, T. P. Visible Light Photocatalysis of $[2+2]$ Styrene Cycloadditions by Energy Transfer. Angew. Chem., Int. Ed. 2012, 51, 10329-10332. For selected examples utilizing other iridium-based catalysts for energy transfer catalysis, see: (o) Nicastri, M. C.; Lehnherr, D.; Lam, Y.-H.; DiRocco, D. A.; Rovis, T. Synthesis of Sterically Hindered Primary Amines by Concurrent Tandem Photoredox Catalysis. J. Am. Chem. Soc. 2020, 142, 987-998. (p) Hörmann, F. M.; Chung, T. S.; Rodriguez, E.; Jakob, M.; Bach, T. Evidence for Triplet Sensitization in the Visible-Light-Induced $[2+2]$ Photocycloaddition of Eniminium Ions. Angew. Chem., Int. Ed. 2018, 57, 827-831. (q) Zhu, S.; Pathigoolla, A.; Lowe, G.; Walsh, D. A.; Cooper, M.; Lewis, W.; Lam, H. W. Sulfonylative and Azidosulfonylative Cyclizations by Visible-Light-Photosensitization of Sulfonyl Azides 
in THF. Chem. - Eur. J. 2017, 23, 17598-17604. (r) Skubi, K. L.; Kidd, J. B.; Jung, H.; Guzei, I. A.; Baik, M.-H.; Yoon, T. P. Enantioselective Excited-State Photoreactions Controlled by a Chiral Hydrogen-Bonding Iridium Sensitizer. J. Am. Chem. Soc. 2017, 139, 17186-17192. (s) Lei, T.; Zhou, C.; Huang, M.-Y.; Zhao, L.-M.; Yang, B.; Ye, C.; Xiao, H.; Meng, Q.-Y.; Ramamurthy, V.; Tung, C.$\mathrm{H}$.; Wu, L.-Z. General and Efficient Intermolecular $[2+2]$ Photodimerization of Chalcones and Cinnamic Acid Derivatives in Solution through Visible-Light Catalysis. Angew. Chem., Int. Ed. 2017, 56, 15407-15410. (t) Scholz, S. O.; Farney, E. P.; Kim, S.; Bates, D. M.; Yoon, T. P. Spin-Selective Generation of Triplet Nitrenes: Olefin Aziridination through Visible-Light Photosensitization of Azidoformates. Angew. Chem., Int. Ed. 2016, 55, 2239-2242.

(9) Triplet lifetime: $\tau=2300 \mathrm{~ns} ; E_{\mathrm{T}}=60.1 \mathrm{kcal} / \mathrm{mol}$, see: (a) Day, J. I.; Teegardin, K.; Weaver, J.; Chan, J. Advances in Photocatalysis: A Microreview of Visible Light Mediated Ruthenium and Iridium Catalyzed Organic Transformations. Org. Process Res. Dev. 2016, 20, 1156-1163. (b) Singh, A.; Teegardin, K.; Kelly, M.; Prasad, K. S.; Krishnan, S.; Weaver, J. D. Facile synthesis and complete characterization of homoleptic and heteroleptic cyclometalated Iridium(III) complexes for photocatalysis. J. Organomet. Chem. 2015, 776, 51-59. (c) Prier, C. K.; Rankic, D. A.; MacMillan, D. W. C. Visible Light Photoredox Catalysis with Transition Metal Complexes: Applications in Organic Synthesis. Chem. Rev. 2013, 113, 5322-5363. (d) Lowry, M. S.; Hudson, W. R.; Pascal, R. A.; Bernhard, S. Accelerated Luminophore Discovery through Combinatorial Synthesis. J. Am. Chem. Soc. 2004, 126, 14129-14135.

(10) (a) Jespersen, D.; Keen, B.; Day, J. I.; Singh, A.; Briles, J.; Mullins, D.; Weaver, J. D. Solubility of Iridium and Ruthenium Organometallic Photoredox Catalysts. Org. Process Res. Dev. 2019, 23, 1087-1095. (b) Hans Wedepohl, K. The composition of the continental crust. Geochim. Cosmochim. Acta 1995, 59, 1217-1232.

(11) (a) Hermann, J. C.; Chen, Y.; Wartchow, C.; Menke, J.; Gao, L.; Gleason, S. K.; Haynes, N.-E.; Scott, N.; Petersen, A.; Gabriel, S.; Vu, B.; George, K. M.; Narayanan, A.; Li, S. H.; Qian, H.; Beatini, N.; Niu, L.; Gan, Q.-F. Metal Impurities Cause False Positives in HighThroughput Screening Campaigns. ACS Med. Chem. Lett. 2013, 4, 197-200. (b) Abernethy, D. R.; Destefano, A. J.; Cecil, T. L.; Zaidi, K.; Williams, R. L. Metal Impurities in Food and Drugs. Pharm. Res. 2010, 27, 750-755.

(12) Recently, a few approaches focused on immobilizing the iridium catalyst on polymers to recycle the catalyst and make iridium catalysis more sustainable, underlining the need for alternatives: (a) Xu, Z.-Y.; Luo, Y.; Zhang, D.-W.; Wang, H.; Sun, X.-W.; Li, Z.-T. Iridium complex-linked porous organic polymers for recyclable, broad-scope photocatalysis of organic transformations. Green Chem. 2020, 22, 136-143. (b) Zhi, P.; Xi, Z.-W.; Wang, D.-Y.; Wang, W.; Liang, X.-Z.; Tao, F.-F.; Shen, R.-P.; Shen, Y.-M. Vilsmeier-Haack reagent mediated synthetic transformations with an immobilized iridium complex photoredox catalyst. New J. Chem. 2019, 43, 709717.

(13) Uoyama, H.; Goushi, K.; Shizu, K.; Nomura, H.; Adachi, C. Highly efficient organic light-emitting diodes from delayed fluorescence. Nature 2012, 492, 234-238.

(14) For a summary of selected properties, see Supporting Information 2. For key references, see: (a) Lu, J.; Pattengale, B.; Liu, Q.; Yang, S.; Shi, W.; Li, S.; Huang, J.; Zhang, J. Donor-Acceptor Fluorophores for Energy-Transfer-Mediated Photocatalysis. J. Am. Chem. Soc. 2018, 140, 13719-13725. (b) Luo, J.; Zhang, J. DonorAcceptor Fluorophores for Visible-Light-Promoted Organic Synthesis: Photoredox/Ni Dual Catalytic $\mathrm{C}\left(\mathrm{sp}^{3}\right)-\mathrm{C}\left(\mathrm{sp}^{2}\right)$ Cross-Coupling. ACS Catal. 2016, 6, 873-87. (c) Lee, K.; Kim, D. LocalExcitation versus Charge-Transfer Characters in the Triplet State: Theoretical Insight into the Singlet-Triplet Energy Differences of Carbazolyl-Phthalonitrile-Based Thermally Activated Delayed Fluorescence Materials. J. Phys. Chem. C 2016, 120, 28330-28336. (d) Huang, S.; Zhang, Q.; Shiota, Y.; Nakagawa, T.; Kuwabara, K.; Yoshizawa, K.; Adachi, C. Computational Prediction for Singlet- and Triplet-Transition Energies of Charge-Transfer Compounds. J. Chem.
Theory Comput. 2013, 9, 3872-3877. For a recent example of an organic sensitizer with a triplet energy lower than that of $2 \mathrm{CzPN}$ used in a not-dearomative process, see: (e) Chen, D.-F.; Chrisman, C. H.; Miyake, G. M. Bromine Radical Catalysis by Energy Transfer Photosensitization. ACS Catal. 2020, 10, 2609-2614.

(15) Zhang, Z.; Zhang, J.; Wu, B.; Li, X.; Chen, Y.; Huang, J.; Zhu, L.; Tian, H. Diarylethenes with a Narrow Singlet-Triplet Energy Gap Sensitizer: a Simple Strategy for Efficient Visible-Light Photochromism. Adv. Opt. Mater. 2018, 6, 1700847.

(16) Iyer, A.; Clay, A.; Jockusch, S.; Sivaguru, J. Evaluating brominated thioxanthones as organo-photocatalysts. J. Phys. Org. Chem. 2017, 30, No. e3738.

(17) Beesley, R. M.; Ingold, C. K.; Thorpe, J. F. The formation and stability of spiro-compounds. J. Chem. Soc., Trans. 1915, 107, 10801106.

(18) For a review about photochemical cycloadditions of allenes, see: (a) Alcaide, B.; Almendros, P.; Aragoncillo, C. Exploiting [2+2] cycloaddition chemistry: achievements with allenes. Chem. Soc. Rev. 2010, 39, 783-816. For UV-light mediated dearomative cycloaddition of allenes to saliyclaldehydes, see: (b) Streit, U.; Birbaum, F.; Quattropani, A.; Bochet, C. G. Photocycloaddition of Arenes and Allenes. J. Org. Chem. 2013, 78, 6890-6910. (c) Birbaum, F.; Neels, A.; Bochet, C. G. Photochemistry of Allenyl Salicylaldehydes. Org. Lett. 2008, 10, 3175-3178. For triplet sensitized dearomative cycloaddition of allenes to indoles, see: (d) Arai, N.; Ohkuma, T. Stereoselective preparation of methylenecyclobutane-fused angular tetracyclic spiroindolines via photosensitized intramolecular $[2+2]$ cycloaddition with allene. Tetrahedron Lett. 2019, 60, 151252. (e) Arai, N.; Ohkuma, T. Stereoselective Construction of Methylenecyclobutane-Fused Indolines through Photosensitized $[2+2]$ Cycloaddition of Allene-Tethered Indole Derivatives. Org. Lett. 2019, $21,1506-1510$. For a recent example of visible-light triplet sensitized allene chemistry, see: (f) Li, X.; Jandl, C.; Bach, T. Visible-LightMediated Enantioselective Photoreactions of 3-Alkylquinolones with 4-O-Tethered Alkenes and Allenes. Org. Lett. 2020, 22, 3618-3622. 